\title{
Kapsül Ağları Kullanılarak EEG Sinyallerinin Sınıflandırılması
}

\author{
Suat TORAMAN* \\ Enformatik Bölümü, Fırat Üniversitesi, Elazığ, Türkiye \\ *storaman@firat.edu.tr
}

(Geliș/Received: 20/12/2019;

Kabul/Accepted: 02/02/2020)

\begin{abstract}
Öz: Epilespi dünyadaki her yüz kişiden birinin sıkıntı çektiği en yaygın nörolojik hastalıklardan biridir. Gerçekleşecek bir nöbetin önceden tahmin edilebilmesi, epilepsi hastalarının yaşam kalitesinin artırılmasında önemli bir rol oynayacaktır. Ayrıca, etkili bir nöbet tahmin sistemi, hastalığın daha kontrol edilebilir olmasını sağlayacaktır. Bu çalışmada, Elektroansefalogram (EEG) sinyallerindeki interiktal ve preiktal beyin aktivitelerini ayırt etmek için bir yöntem önerilmiştir. Önerilen yöntemde, yeni bir sinir ağı modeli olan kapsül ağları kullanılmıştır. Preiktal aktivite, nöbet başlangıcından 30dk ileride seçilmiştir. Preiktal ve interiktal kısımlar kayan pencere ile segmentlere ayrılmış ve her segmentin spektrogram görüntüleri elde edilmiştir. Spektrogram görüntüleri, kapsül ağları kullanılarak C3-P3 için ortalama \%94.05 doğruluk ile sınıflandırılmıştır. Bu çalışma ile kapsül ağlarının preiktal/interiktal sınıflandırma başarımı incelenmiştir. Elde edilen sonuçlar, kapsül ağlarının epilepsinin tahmini için umut verici bir yöntem olduğunu göstermektedir.
\end{abstract}

Anahtar Kelimeler: EEG, Epilepsi, Kapsül ağları, Preiktal/interiktal tanıma

\section{Classification of EEG Signals Using Capsule Networks}

\begin{abstract}
Epilepsy is one of the most common neurological diseases in which one in every hundred people in the world suffers. Predicting a seizure will play an important role in improving the quality of life of epilepsy patients. In addition, an effective seizure prediction system will ensure that the disease is more controllable. In this study, a new method was proposed to differentiate the interictal and preictal activities of electroencephalogram (EEG) signals. The proposed method uses capsule networks that a new model of neural network. Preictal activity was selected $30 \mathrm{~min}$ before seizure onset. The preictal and interictal sections were segmented with a sliding window and then each segment was transformed into spectrograms. Spectrogram images were classified with an average accuracy of $94.05 \%$ for C3-P3 using capsule networks. In this study, preictal/interictal classification performance of capsule networks was investigated. The results show that capsule networks are a promising method for the prediction of epilepsy.
\end{abstract}

Key words: EEG, Epilepsy, Capsule networks, Preictal/Interictal recognition

\section{Giriş}

Epilepsi, dünya genelinde milyonlarca insanın sıkıntı çektiği merkezi sinir sisteminde görülen nörolojik bir rahatsızlıktır [1]. Epileptik nöbetler, beyindeki nöronlar normal çalışırken aniden bu nöronların yanlış çalışması sonucunda oluşmaktadır $[1,2]$. Elektroensefalogram (EEG), beyin aktivitesindeki değişikliklerin incelenmesi veya olabilecek bir nöbetin belirlemesinde kullanılan bir yöntemdir. Nöbet tahmininde önemli olan preiktal durumun belirlenebilmesidir. Preiktal, beyin aktivitelerinde değişikliğin oluşmaya başladığı durumdur. Bu nedenle etkili bir nöbet tahmin sistemi için önemli bilgiler içeren preiktal durumun belirlenebilmesi büyük öneme sahiptir. EEG sinyalleri kullanılarak beyin aktivitesindeki değişikliklerin tespit edilmesi için çeşitli geleneksel özellik çıkarım yöntemleri kullanmıştır. Liu ve diğ. çok kanallı intrakranial EEG sinyalini dalgacık dönüşümü ile alt batlarına ayırmıştır ve daha sonra çeşitli özellikler çıkararak EEG sinyallerini sınıflandırmıştır [3]. Zhang ve diğ, preiktal ve interiktal ayrımı için EEG sinyallerinin spektral analizini kullanmıştır [4]. Cho ve diğ. interiktal ve preiktal sınıflandırma için faz kilitleme değerleri kullanmıştır [5]. Tsiouris ve diğ. Frekans domaini, zaman domain ve graf teorisini ile elde ettikleri özellikleri kullanarak preiktal ve interiktal durumları sınıflandırmıştır [2]. Bu yöntemler ile EEG sinyalleri farklı teknikler kullanılarak sınıflandırılmıştır [6,7]. GPU (Grafik işlem birimi) teknolojisinde gelişmelere paralel olarak son yıllarda derin öğrenme kullanılarak gerçekleştirilen sinyal / görüntü işleme ve sınıflandırma uygulamaları da oldukça artmıştır. Başarılı sonuçlar üretmesi nedeniyle derin öğrenme modelleri birçok alanda olduğu gibi tıp alanında da oldukça tercih edilmektedir [8-11]. Derin öğrenme modelleri sayesinde geleneksel yöntemlerde olduğu gibi elle tasarlanmış özellik çıkarımına ihtiyaç kalmamıştır [8,12]. Son zamanlarda, EEG sinyallerinin incelenmesinde derin öğrenme yöntemleri de sıkça kullanılmaya başlanmıştır

\footnotetext{
* Sorumlu yazar: storaman@ @irat.edu.tr. Yazarın ORCID Numarası: 0000-0002-7568-4131
} 
[13,14]. EEG sinyallerinin 1 boyutlu sinyal veya 2 boyutlu resim formunda incelenmesine yönelik çeşitli uygulamalar bulunmaktadır. Özal ve diğ. bir boyutlu ESA modelini kullanarak EEG sinyallerini normal ve abnormal olarak sınıflandırmıştır [15]. Toraman ve diğ. konuşma lateralitesinin belirlenmesi için EEG sinyallerini iki boyutlu spektrogram görüntüsüne çevirip özellik çıkramı yaptıktan sonra sınıflandırmıştır [16]. İhsan Ullah ve diğ. EEG sinyallerini otomatik olarak normal, iktal ve interiktal sınıflandırmıştır [17]. Bu çalışmada ise, nöbet tahmini için önemli olan preiktal/interiktal aktivite belirlenmesine yönelik yeni bir sinir ağı modeli olan kapsül ağları kullanılmıştır. Kapsül ağlarının eğitilmesi için EEG sinyalleri spektrogram görüntülerine dönüştürülmüş ve kapsül ağlarına giriş olarak uygulanmıştır. Literatür araştırmasında, kapsül ağları EEG sinyallerinden duygu tahmini [18] ve motor imgeleme [19] gibi konularda çalışılmışsa da, preiktal ve interiktal EEG sinyallerin sınıflandırılmasında kullanılmamıştır. Çalışmanın diğer bir katkısı, geleneksel EEG sınıflandırma yöntemlerinde olduğu gibi özellik çıkarımına gereksinim duyulmamasıdır. Sinyalden özellik çıkarımında, ayırt edici yöntemin belirlenmesi, uzman tecrübesi başarımı etkileyen önemli faktörlerdir. Bu çalışmada, elle özellik çıkarımına ihtiyaç duyulmadan kapsül ağları verilen giriş görüntülerini yüksek doğruluk ile sınıflandırmıştır. Çalışmanın geri kalanı aşağıdaki şekilde düzenlenmiştir. Bölüm 2'de, veri seti, preiktal-interiktal durum seçimi ve kapsül ağlarına ilişkin temel bilgiler verilmiştir. Bölüm 3’te, deneysel sonuçlar ve tartışma, Bölüm 4'te sonuçlar sunulmuştur.

\section{Materyal ve Metot}

\subsection{Veri seti}

Çalışmada, Boston Çocuk Hastanesinde (CHB) nöbet geçiren beş çocuk denekten alınan EEG veri kümesi kullanılmıştır [20]. Veriler, 10-20 EEG elektrot pozisyon sistemi kullanılarak 18 ile 23 kanallı ve 256 örnekleme frekansı ile alınmıştır. CHB-MIT EEG kayıtların çoğu birer saatlik dönemlerden (epoch) oluşurken, bazıları iki ile dörder saatlik dönemlerden oluşmaktadır. Her hastanın nöbet başlangıcı klinik uzmanı tarafindan işaretlenmiştir. $\mathrm{Bu}$ bilgiler veri tabanındaki ek açıklama dosyasında bulunmaktadır. Bu çalışma için chb01, chb02, chb03, chb04 ve chb05 vakaları kullanılmıştır. Seçilen vakaların üç farklı kanal (FP1-F7, F7-T7, C3-P3) bilgisi incelenmiştir. Epilepsi hastalarının beyin aktiviteleri interiktal, preiktal, iktal ve postiktal olmak üzere dört durum içerir. Preiktal, nöbet başlangıcından önce gerçekleşen aktiviteler ifade etmektedir. İktal, nöbetin başladığ 1 ve bitti ana kadar olan durumu, postiktal, nöbet sonrası durumu ve interiktal ise diğer üç durum dışında kalan normal beyin aktivitelerini ifade etmektedir. Çalışmada kullanılan preiktal ve interiktal sinyallerine ait temsili örnekler Şekil 1'de verilmiştir.
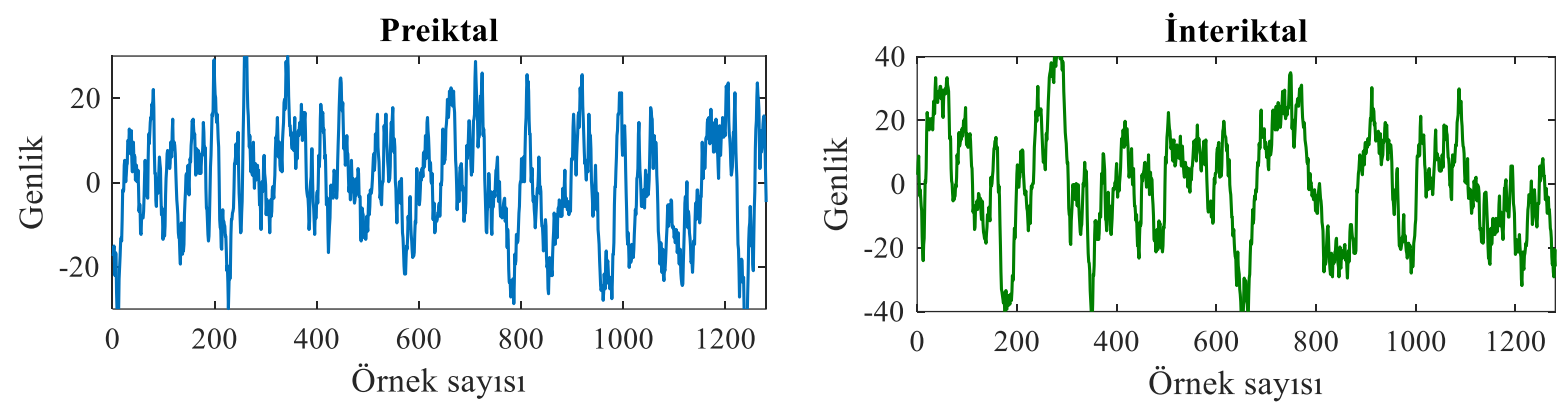

Şekil 1. 5sn'lik preiktal ve interiktal sinyal örneği

\subsection{Sinyal bölümleme ve spektrogram}

Çalışma için preiktal eğitim aralığı nöbet başlangıcından önceki 30dk da bitecek şekilde 30dk'llk aralık seçilmiştir. İnteriktal ise nöbetten en az 2 saat uzaklıkta olacak şekilde belirlenmiştir. Veri setinde birbirine yakın birçok nöbet olduğu için önce gerçekleşen nöbet kullanılmıştır. Yukarıdaki şartlara göz önüne alındığında chb01 için 5 , chb02 ve chb03 için 2, chb04 için 3 ve chb05 için ise 4 nöbet bulunmaktadır. Her nöbet öncesi $30 \mathrm{dk}$ 'llk preiktal ve interiktal aralıklar örtüşmesiz kayan pencere yöntemi ile 5sn'lik bölümlere ayrılmıştır. Chb01 için 1800 preiktal ve 1800 interiktal bölüm oluşurken, chb02 ve chb03 için 720, chb04 için 1080 ve chb05 için 1440 bölüm oluşmuştur. Her bir preiktal ve interiktal sinyal parçası $16 \mathrm{~ms}$ pencere genişliği (hamming), $8 \mathrm{~ms}$ binişme ve FFT sayısı 512 olacak şekilde spektrograma dönüştürülmüştür. Renk haritası olarak viridis kullanılmıştır. Spektrogram görüntüleri kapsül ağları için $64 \times 64$ piksel olacak şekilde boyutlandırılmıştır. Şekil 2'de spektrograma dönüştürülmüşs sinyal örneği verilmiştir. 


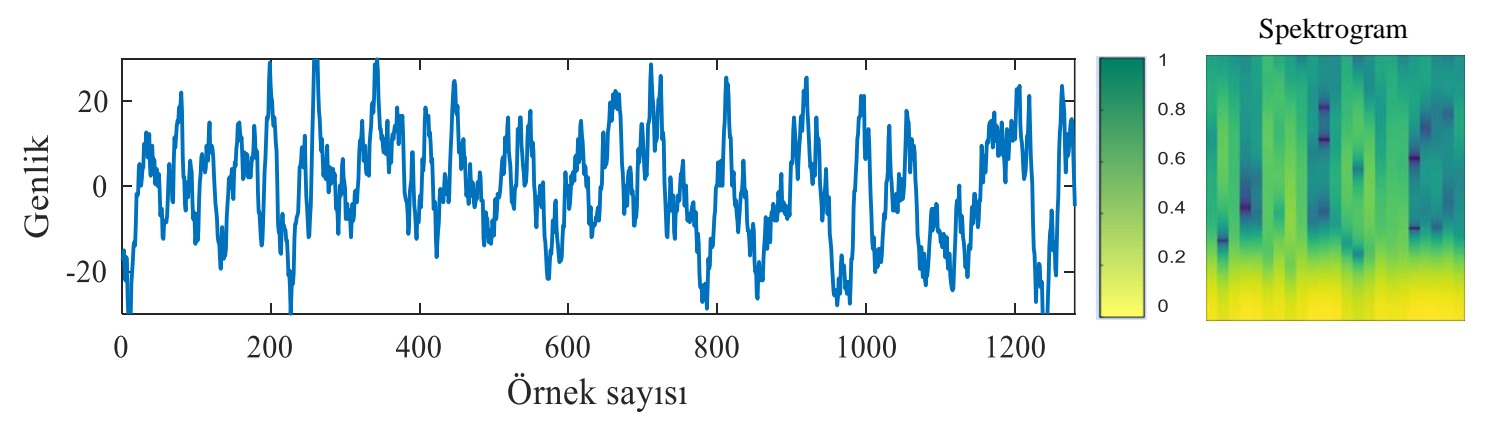

Şekil 2. EEG sinyaline ait bir spektrogram örneği

\subsection{Kapsül ağları}

ESA'lar, ilk evrişim katmanında görüntüdeki basit özellikleri (kenar, köşe vb.) öğrenir. Daha karmaşık özellikleri öğrenmek için doğrusal olmayan aktivasyon fonksiyonu kullanılır. Verideki önemli bilgiyi ön plana çıkarmak için havuzlama uygulanır. Art arda eklenmiş bloklar sayesinde bir önceki bloktan gelen bilgiden özellik çıkarımı devam eder. Böylece ağ daha karmaşı özellikleri öğrenir. ESA'lar görüntüdeki nesneleri sınıflandırmada başarılıdır. Fakat ESA görüntüdeki nesnelerin konumlarını veya nesnenin parçaları arasındaki ilişkiyi ortaya koyamaz. Bu eksiklikten yola çıkarak Hinton ve ark. görüntüdeki nesnelerin konumlarını korumak, nesnedeki özelliklerinin hiyerarşik ilişkileri modellemek için kapsül ağları olarak adlandırılan yeni bir sinir ağı modeli geliştirmiş̧tir [21,22]. Kapsül ağları, birçok nöronu bir arada tutan kapsül olarak adlandırılan yapılardan oluşmaktadır. Mevcut ESA'ların çıkışı skaler bir değer iken, kapsül ağlarının çıkışı vektöreldir. ESA'lar aktivasyon fonksiyonu olarak ReLu, Sigmoid, Tanjant gibi skaler girdi alan fonksiyonları kullanmaktadır. Kapsül ağlarında ise ezme (squashing) olarak adlandırılan vektörel bir aktivasyon fonksiyonu kullanılmaktadır (Denklem 1) $[21,23]$.

$$
v_{j}=\frac{\left\|s_{j}\right\|^{2}}{1+\left\|s_{j}\right\|^{2}} \frac{s_{j}}{\left\|s_{j}\right\|}
$$

Denklemde, $s_{j}$ kapsül girişi ve $v_{j}$ ise kapsülün çıkış vektörünü gösterir. Çıkış vektörü $\left(v_{j}\right)$, görüntüde bir nesne varsa uzun vektörleri 1'e doğru daraltırken, görüntüde nesne bulunmuyorsa kısa vektörleri sıfira doğru baskılar [21,23]. Kapsül ağlarında, belirli bir sınıftaki nesnelerin mevcut olup olmadığını belirlemek için Denklem2 'deki ayrı bir marj kaybı önerilmiştir.

$$
L_{k}=T_{k} \max \left(0, m^{+}-\left\|v_{k}\right\|\right)^{2}+\lambda\left(1-T_{k}\right) \max \left(0,\left\|v_{k}\right\|-m^{-}\right)^{2}
$$

Burada eğer bir k sınıfı yoksa $T_{k}=0$, varsa, $T_{k}=1$ ve $m^{+}=0.9$ ve $m^{-}=0.1$ 'dir. Hesaplanan vektörlerin uzunluğu, görüntüdeki nesnenin, o kısmında bulunma olasılığını gösterir. Vektörün yönü, nesnenin doku, poz, renk, vb. bilgilerini içermektedir [22]. Çalışmada kullanılan kapsül ağ yapısı Şekil 3'de gösterilmiştir.

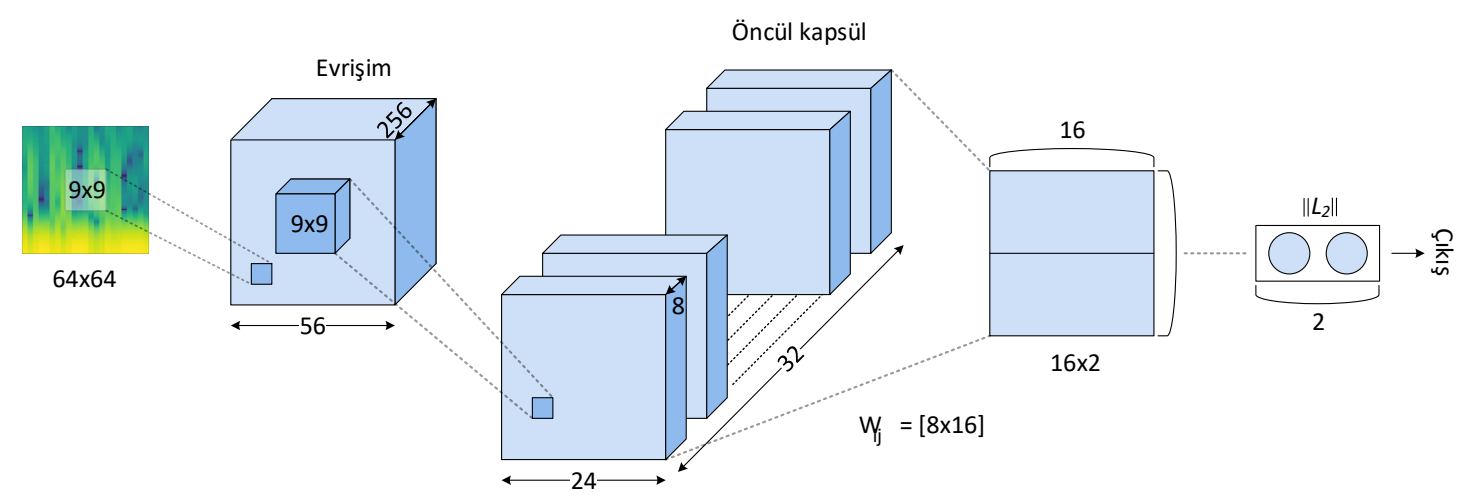

Şekil 3. EEG sinyallerinin spektrogram görüntülerinin sınıflandırılması için kapsül ağ yapısı 


\section{Deneysel Sonuç ve Tartışma}

Çalışmada, EEG sinyallerinin preiktal ve interiktal aktivitelerini kapsül ağları ile sınıflandırma işlemi gerçekleştirilmiştir. CHB-MIT veri setindeki beş vakanın (chb01, chb02, chb03, chb04, chb05) FP1-F7, F7-T7, C3-P3 kanal bilgileri incelenmiştir. Örneğin chb01 vakasında, herhangi bir nöbetten 30dk uzaklıkta bitecek şekilde, şartlara uygun beş nöbet bulunmaktadır. Beş nöbet için (5x30dk) 150dk preiktal bölge alınmıştır. Dengeli bir eğitim aşaması için aynı uzunlukta interiktal aktivite seçilmiştir. İnteriktal bölge, nöbetlerden en az iki saat uzaklıkta olacak şekilde $150 \mathrm{dk}$ seçilmiştir. 150dk'llk preiktal ve interiktal bölgeler 5sn'lik örtüşmesiz kayan pencere yöntemi kullanılarak 1800 parçaya ayrılmıştır. Her bir parça spektrograma dönüştürülmüştür. Sonuç olarak chb01 vakası için 3600 spektrogram görüntüsü elde edilmiştir. Aynı işlemler diğer vakalar içinde gerçekleştirilmiştir. Chb01 vakasının eğitim sürecine ait bir katlama (fold) için performans grafiği Şekil 4'de gösterilmiştir.

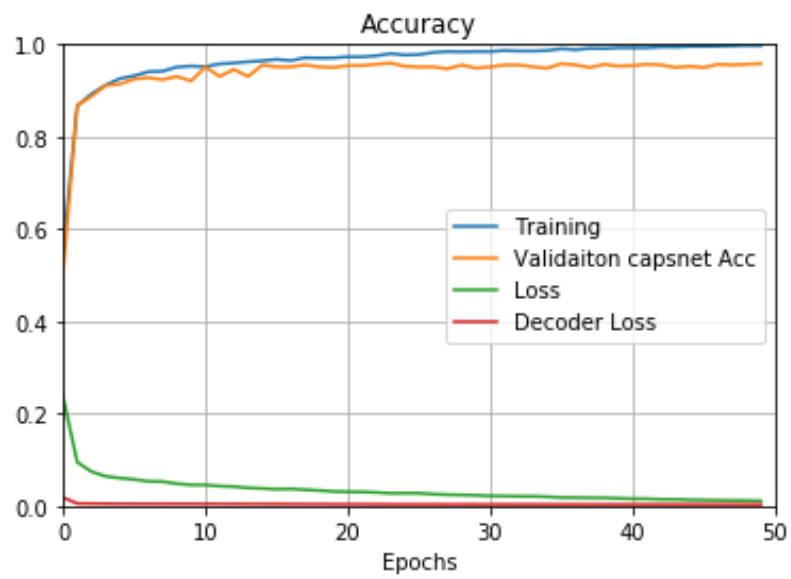

Şekil 4. Chb01 vakasının bir katlama için eğitim ve kayıp grafikleri

Beş vakanın her üç kanal için elde edilen doğruluk, duyarlılık ve özgüllük sonuçları Tablo 1'de verilmiştir. Önerilen yöntemin sonuçlarının daha nesnel olarak değerlendirilebilmesi için $k$-katlamalı çapraz doğrulama yöntemi kullanılmıştır. $k$ değeri 5 olarak belirlenmiștir. Tablo 1'de görüldüğü gibi en yüksek sınıflama doğruluğuna chb02'nin FP1-F7 ve C3-P3 kanallarında ulaşılmıştır. En düşük doğruluk chb05 vakasında görülmektedir. Hangi kanalın vaka incelemesinde daha etkili olduğunu incelemek için Tablo 2'de beş vaka için her bir kanalın ortalama değeri hesaplanmıştır.

Tablo 1. Beş vakanın üç ayrı kanal için sınıflandırma performansları

\begin{tabular}{ccccc}
\hline Vaka & Kanal & Duyarlılı (\%) & Özgüllük (\%) & Doğruluk (\%) \\
\hline \multirow{3}{*}{ chb01 } & FP1-F7 & 97.38 & 95.10 & $96.25 \pm 0.64$ \\
& F7-T7 & 92.50 & 94.99 & $93.75 \pm 0.85$ \\
& C3-P3 & 99.66 & 99.77 & $99.72 \pm 0.20$ \\
\hline \multirow{3}{*}{ chb02 } & FP1-F7 & 100.0 & 100.0 & $100.0 \pm 0.00$ \\
& F7-T7 & 100.0 & 99.86 & $99.93 \pm 0.14$ \\
& C3-P3 & 100.0 & 100.0 & $100.0 \pm 0.00$ \\
\hline \multirow{3}{*}{ chb03 } & FP1-F7 & 86.66 & 86.52 & $86.60 \pm 1.21$ \\
& F7-T7 & 86.24 & 81.38 & $83.82 \pm 2.25$ \\
& C3-P3 & 100.0 & 98.75 & $99.38 \pm 0.64$ \\
\hline \multirow{4}{*}{ chb04 } & FP1-F7 & 95.37 & 99.81 & $97.73 \pm 0.90$ \\
& F7-T7 & 87.22 & 96.11 & $91.67 \pm 0.96$ \\
& C3-P3 & 94.81 & 81.57 & $88.19 \pm 1.25$ \\
\hline \multirow{3}{*}{ chb05 } & FP1-F7 & 85.76 & 70.00 & $77.88 \pm 1.15$ \\
& F7-T7 & 84.79 & 73.40 & $79.10 \pm 1.25$ \\
& C3-P3 & 93.75 & 72.22 & $82.99 \pm 2.22$ \\
\hline
\end{tabular}


Tablo 2'de görüldüğü gibi, en yüksek ortalama doğruluk \%94.05 ile C3-P3 kanalında elde edilmiştir. Diğer iki kanalında ortalama doğruluk değerlerine bakıldığı zaman bu kanallarında preiktal/interiktal ayrımında etkili bir şekilde kullanılabileceği görülmektedir. Şekil 5 'te vakaların doğruluk değerleri grafiksel olarak karşıllaştırılmıştır.

Tablo 2. Her üç kanalın ortalama performans değerleri

\begin{tabular}{llll}
\hline Ölçütler & \multicolumn{1}{c}{ FP1-F7 } & \multicolumn{1}{c}{ F7-T7 } & \multicolumn{1}{c}{ C3-P3 } \\
\hline Duyarlılık (\%) & $93.03 \pm 6.45$ & $90.15 \pm 6.22$ & $97.64 \pm 3.10$ \\
Özgüllük (\%) & $90.28 \pm 12.59$ & $89.15 \pm 11.24$ & $90.46 \pm 12.83$ \\
Doğruluk (\%) & $91.69 \pm 9.26$ & $89.65 \pm 8.24$ & $94.05 \pm 7.95$ \\
\hline
\end{tabular}

Doğruluk (\%)

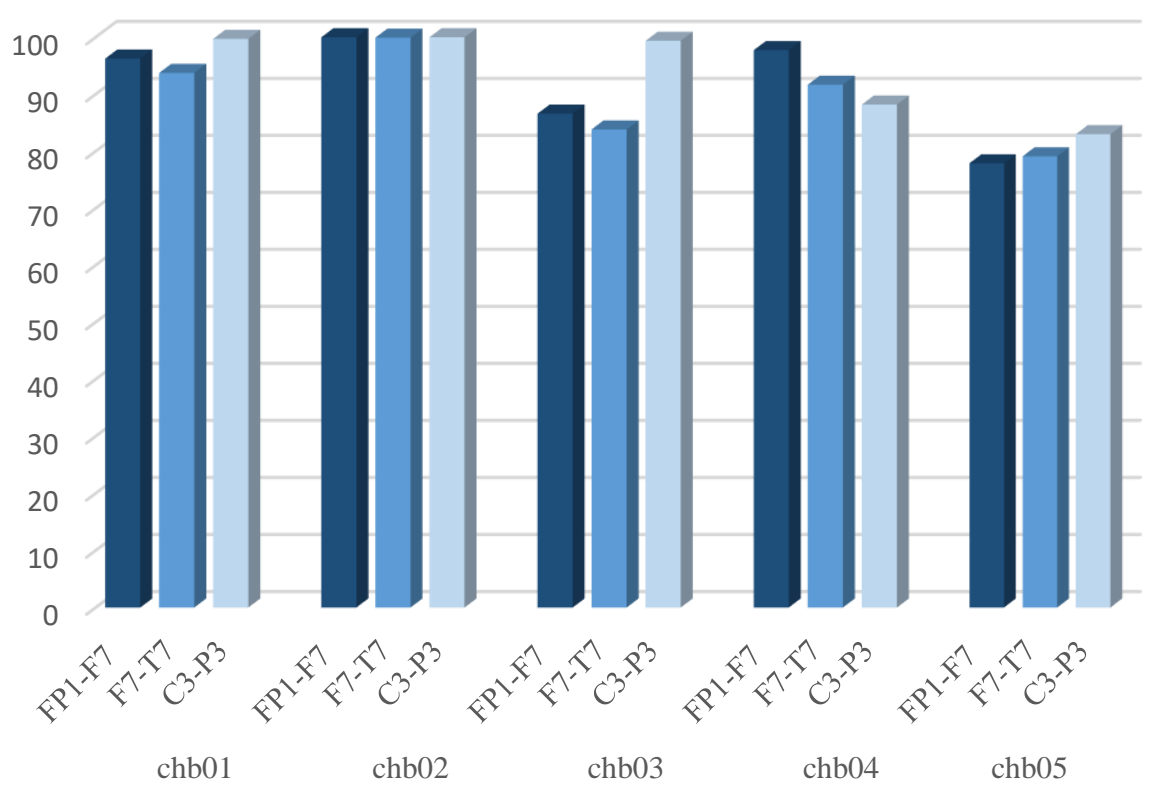

Şekil 5. Beş vakanın her üç kanal için elde edilen doğruluk değerleri

Preiktal/interiktal aktivitelerin sınıflandırılması üzerine geleneksel makine öğrenme tekniklerinin veya yeni teknolojilerin kullanıldığı bazı çalışmalar vardır. Bu çalışmalarda, aşırı öğrenme makineleri (ELM) [24], destek vektör makineleri (DVM) [25], yapay sinir ağları [26] gibi çeşitli sınıflandırma yöntemleri kullanılmıştır. Tablo 3'te, CHB-MIT veri seti kullanılarak gerçekleştirilen preiktal/interiktal sınıflandırması üzerine yapılan çalışmaların sonuçları karşılaştırmalı olarak verilmiştir.

Tablo 3. Preiktal ve interiktal aktivite sınıflandırılması üzerine yapılan önceki çalışmalar

\begin{tabular}{|c|c|c|c|}
\hline Yazarlar & Metotlar & Veri seti & Sonuçlar \\
\hline $\begin{array}{l}\text { Cho et al. [5] } \\
\text { (2017) }\end{array}$ & $\begin{array}{l}\text { PLV (Faz kilitleme } \\
\text { değeri), DVM }\end{array}$ & CHB-MIT & $\begin{array}{l}\text { Doğruluk: } 83.17 \\
\text { Duyarlılık: } 82.44 \\
\text { Özgüllük: } 82.76\end{array}$ \\
\hline $\begin{array}{l}\text { Tsiouris vd. [2] } \\
\text { (2017) }\end{array}$ & $\begin{array}{l}\text { Yerel ve global } \\
\text { özellikler, DVM }\end{array}$ & CHB-MIT & $\begin{array}{l}\text { Doğruluk: --- } \\
\text { Duyarl1l1k: } 85.75 \\
\text { Özgüllük: } 85.75\end{array}$ \\
\hline $\begin{array}{l}\text { Mengie et al. [27] } \\
\text { (2018) }\end{array}$ & ESA & CHB-MIT & $\begin{array}{l}\text { Doğruluk: } 95.60 \\
\text { Duyarll1k: } 94.20 \\
\text { Özgülllük: } 96.60\end{array}$ \\
\hline Önerilen Yöntem & Kapsül ağları & CHB-MIT & $\begin{array}{l}\text { Doğruluk: } 94.05 \\
\text { Duyarlılık: } 97.64 \\
\text { Özgüllük: } 90.46\end{array}$ \\
\hline
\end{tabular}


Tablo 3'te görüldüğü gibi kapsül ağları ile iyi bir sınıflandırma başarımına ulaşılmıştır. Önceki çalışmalarda belirtildiği gibi [2] preiktal durum nöbet başlangıcından iki saat öncesine kadar uzanan geniş bir aralığı kapsamaktadır. Elde edilen sonuçlar bu görüşü desteklemektedir. Bu çalışmanın kısıtlarından biri, veri kümesinin yarım saatlik EEG sinyallerinden oluşmasıdır. Preiktal bölgenin nöbet başlangıcından iki saat öncesine kadar uzandığı düsünülürse, incelenen kısım daha genis bir aralığa yayılabilir. Fakat, aralığın artırılmasının ciddi bir donanımsal kaynak ihtiyacı ve işlem yükü getireceği de göz önünde bulundurulmalıdır. Çalışmanın diğer bir kısıtlaması ise, görüntülerin kapsül ağlarına $64 \times 64$ boyutunda verilmesidir. Resim boyutunun küçülmesi görüntüdeki birçok önemli bilginin kaybolmasına neden olabilmektedir.

\section{Sonuçlar}

Bu çalışmada, EEG sinyal bileşenlerinden preiktal ve interiktal aktivitelerin kapsül ağları kullanılarak sınıflandırıldığı bir yaklaşım önerilmiştir. Bu çalışma ile literatürde yeni bir sinir ağı olan kapsül ağılarının EEG sinyallerinden elde edilen spektrogram görüntülerini sınıflandırma yeteneği incelenmiştir. Sınıflandırma işleminin sonucu, yapılan ön çalışma için tatmin edicidir. Ayrıca, bu çalışmanın diğer bir sonucu, preiktal bölgenin nöbet başlangıcından önceki 30dk da bitecek şekilde seçilmesi ile bu bölgenin, oluşabilecek herhangi bir nöbet için önemli bilgiler içerdiğini göstermektedir. Meydana gelebilecek bir nöbetin önceden tahmin edilmesi hekimlerin hastaya daha etkili bir şekilde müdahale edebilmesi sağlayacaktır. Bu nedenle, kapsül ağlarının, spektrogram görüntülerini sınıflandırma başarımının daha net bir şekilde ortaya konulabilmesi için daha büyük veri setleri ile eğitilmesine ihtiyaç vardır. Büyük veri seti kullanılarak yapılacak bir eğitim, sistemin geçerliliği ve güvenirliğini önemli ölçüde artıracaktır.

\section{Kaynaklar}

[1] Hussain L. Detecting epileptic seizure with different feature extracting strategies using robust machine learning classification techniques by applying advance parameter optimization approach. Cogn Neurodyn 2018;12 (3):271-294.

[2] Tsiouris KM, Pezoulas VC, Koutsouris DD, Zervakis M, Fotiadis DI. Discrimination of Preictal and Interictal Brain States from Long-Term EEG Data. 2017 IEEE 30th International Symposium on Computer-Based Medical Systems (CBMS). IEEE, pp 318-323

[3] Yinxia L, Weidong Z, Qi Y, Shuangshuang C. Automatic Seizure Detection Using Wavelet Transform and SVM in Long-Term Intracranial EEG. IEEE Trans Neural Syst Rehabil Eng 2012;20 (6):749-755.

[4] Zhang Z, Parhi KK. Low-Complexity Seizure Prediction From iEEG/sEEG Using Spectral Power and Ratios of Spectral Power. IEEE Trans Biomed Circuits Syst 2016;10 (3):693-706.

[5] Cho D, Min B, Kim J, Lee B. EEG-Based Prediction of Epileptic Seizures Using Phase Synchronization Elicited from Noise-Assisted Multivariate Empirical Mode Decomposition. IEEE Trans Neural Syst Rehabil Eng 2017;25 (8):13091318.

[6] Ramgopal S, Thome-Souza S, Jackson M, Kadish NE, Sánchez Fernández I, Klehm J, Bosl W, Reinsberger C, Schachter $\mathrm{S}$, Loddenkemper T. Seizure detection, seizure prediction, and closed-loop warning systems in epilepsy. Epilepsy Behav 2014;37 291-307.

[7] Alotaiby TN, Alshebeili SA, Alshawi T, Ahmad I, Abd El-Samie FE. EEG seizure detection and prediction algorithms: a survey. EURASIP J Adv Signal Process 2014;2014 (1):183.

[8] Tan JH, Hagiwara Y, Pang W, Lim I, Oh SL, Adam M, Tan RS, Chen M, Acharya UR. Application of stacked convolutional and long short-term memory network for accurate identification of CAD ECG signals. Comput Biol Med 2018;94 19-26.

[9] Arslan Tuncer S, Akılotu B, Toraman S. A deep learning-based decision support system for diagnosis of OSAS using PTT signals. Med Hypotheses. doi: 10.1016/j.mehy.2019.03.026

[10] Yildirim O, Baloglu UB, Tan R-S, Ciaccio EJ, Acharya UR. A new approach for arrhythmia classification using deep coded features and LSTM networks. Comput Methods Programs Biomed 2019;176 121-133.

[11] Acharya UR, Oh SL, Hagiwara Y, Tan JH, Adeli H, Subha DP. Automated EEG-based screening of depression using deep convolutional neural network. Comput Methods Programs Biomed 2018;161 103-113.

[12] Giri EP, Fanany MI, Arymurthy AM, Wijaya SK. Ischemic stroke identification based on EEG and EOG using ID convolutional neural network and batch normalization. 2016 International Conference on Advanced Computer Science and Information Systems (ICACSIS). IEEE, pp 484-491

[13] Lotte F, Congedo M, Lécuyer A, Lamarche F, Arnaldi B. A review of classification algorithms for EEG-based braincomputer interfaces. J Neural Eng 2007;4 (2):R1-R13.

[14] Acharya UR, Hagiwara Y, Adeli H. Automated seizure prediction. Epilepsy Behav 2018;88 251-261.

[15] Yıldırım Ö, Baloglu UB, Acharya UR. A deep convolutional neural network model for automated identification of abnormal EEG signals. Neural Comput. Appl.

[16] Toraman S, Arslan Tuncer S, Balgetir F. Is it possible to detect cerebral dominance via EEG signals by using deeplearning? Med Hypothesses 2019;131 
[17] Ullah I, Hussain M, Qazi E-H, Aboalsamh H. An automated system for epilepsy detection using EEG brain signals based on deep learning approach. Expert Syst Appl 2018;107 61-71.

[18] Chao H, Dong L, Liu Y, Lu B. Emotion recognition from multiband EEG signals using CapsNet. Sensors 2019;19,2212.

[19] Ha KW, Jeong JW. Motor imagery EEG classification using capsule networks. Sensors 2019; 19(13).

[20] CHB-mit scalp EEG database, Physionet.org, [Online]. Available:https://www. physionet.org/pn6/chbmit. (2010) (accessed 04 April 2019)

[21] Mukhometzianov R, Carrillo J. CapsNet comparative performance evaluation for image classification. arXiv:1805.11195. arXiv.org

[22] Beser F, Kizrak MA, Bolat B, Yildirim T. Recognition of sign language using capsule networks. 26th IEEE Signal Processing and Communications Applications Conference, SIU 2018. pp 1-4

[23] Sabour S, Frosst N, Hinton GE. Dynamic routing between capsules. Advances in Neural Information Processing Systems

[24] Song Y, Zhang J. Discriminating preictal and interictal brain states in intracranial EEG by sample entropy and extreme learning machine. J Neurosci Methods 2016;257 45-54.

[25] Lin L-C, Chen SC-J, Chiang C-T, Wu H-C, Yang R-C, Ouyang C-S. Classification Preictal and Interictal Stages via Integrating Interchannel and Time-Domain Analysis of EEG Features. Clin EEG Neurosci 2017;48 (2):139-145.

[26] Bou Assi E, Gagliano L, Rihana S, Nguyen DK, Sawan M. Bispectrum Features and Multilayer Perceptron Classifier to Enhance Seizure Prediction. Sci Rep 2018;8 (1):15491.

[27] Zhou M, Tian C, Cao R, Wang B, Niu Y, Hu T, Guo H, Xiang J. Epileptic Seizure Detection Based on EEG Signals and CNN. Front Neuroinform 2018;12 